\title{
Determination of Benzylpenicillin Potassium Residues in Duck Meat Using Surface Enhanced Raman Spectroscopy with Au Nanoparticles
}

\author{
Yijie Peng, Muhua Liu, Jinhui Zhao, Haichao Yuan, Yao Li, \\ Jinjiang Tao, and Hongqing Guo \\ Optics-Electrics Application of Biomaterials Lab, College of Engineering, Jiangxi Agricultural University, Nanchang, \\ Jiangxi 330045, China
}

Correspondence should be addressed to Jinhui Zhao; zjhxiaocao@sina.com

Received 26 December 2015; Revised 20 March 2016; Accepted 10 April 2016

Academic Editor: Muhammad Tahir

Copyright (C) 2016 Yijie Peng et al. This is an open access article distributed under the Creative Commons Attribution License, which permits unrestricted use, distribution, and reproduction in any medium, provided the original work is properly cited.

\begin{abstract}
A new method using surface enhanced Raman spectroscopy (SERS) with Au nanoparticles was established for the rapid detection of benzylpenicillin potassium (PG) residues in duck meat. Au nanoparticles were used as SERS enhancement substrate, and the maximum absorption peak of Au nanoparticles using the UV-Vis spectrophotometer was $548 \mathrm{~nm}$. In the research, the SERS spectra of PG solutions and PG duck meat extract as well as their vibrational assignment were analyzed. The effects of Au nanoparticles addition, sample addition, $\mathrm{NaCl}$ solution addition, and adsorption time on the SERS intensities of PG duck meat extract were discussed. It is revealed that a good linearity can be obtained between the SERS intensities at $993 \mathrm{~cm}^{-1}$ and the PG residues concentrations $\left(0.5 \sim 15.0 \mathrm{mg} \cdot \mathrm{L}^{-1}\right)$ detected in duck meat extract. The linear equation was $Y=831.68 X+1997.1$, and the determination coefficient was 0.9553 . The determination coefficient of PG in duck meat extract between the actual values and the predictive values was 0.9757 , and the root mean square error (RMSEP) was $0.6496 \mathrm{mg} / \mathrm{L}$. The recovery rate of PG in duck meat extract was 90 121\%. The results showed that the method using SERS with Au nanoparticles could pave a new way for the rapid detection of PG residues in duck meat.
\end{abstract}

\section{Introduction}

Penicillin is a type of $\beta$-lactam antimicrobial drugs and, as one of the most output and the most widely used antibiotics, has been successfully applied to treat bacterial infections in both human and animals, such as gastrointestinal, urethra, and respiratory tract infections $[1,2]$. Because of its high solubility, benzylpenicillin potassium (PG) is one of the most used penicillins and has been regarded as the best choice of treating duck diseases [2-4]. The penicillin residues are strictly controlled and limited in China, with a maximum residue limit (MRL) of penicillin residues in animal foods of $50 \mu \mathrm{g} \cdot \mathrm{L}^{-1}$, according to the regulation of China's Ministry of Agriculture [5]. If the amount of penicillin is not rationally used in the duck-raising process, violation residues in duck meat will be caused and the penicillin residues in duck meat would endanger human's health.

Currently, the main methods reported for the detection of penicillin residues in animal foods include the high-performance liquid chromatography (HPLC) $[1,6]$, microbial method [7], enzyme-linked immunosorbent assay [8], and electrochemical immunosensor [5]. The advantages of these techniques are the sensitivity and practicality; however, these methods are also suffering several drawbacks, such as complex pretreatment and unsatisfactory costeffectiveness. Therefore, it is very urgent to establish a new method for the simple, rapid, and accurate detection of penicillin residues in duck meat.

Surface enhanced Raman spectroscopy (SERS) is an interesting phenomenon that some molecules and functional groups were adsorbed onto the roughened surface of a suitable metal, such as gold, silver, or copper, and the intensities of their Raman signals can be greatly enhanced. This detection technique, which possesses many advantages such as convenient operation, high accuracy rate, fast testing velocity, and the portable instrument, has been widely applied in the biological engineering, medical, food detection, and 
other research works [9-11]. Di Anibal et al. adopted a screening tool to detect Sudan I dye in culinary spices using SERS and multivariate analysis [12]. Tang et al. applied the alkaline silver colloid as SERS enhancement substrate to detect the melamine in milk [13]. Zhu used SERS to detect the nitrofuran antibiotics residues in chicken, fish, and shrimp meat [14]. In this research, Au nanoparticles were used as the SERS enhancement substrate and PG in duck meat extract was used as the research object, and a new method using SERS with Au nanoparticles was established for the rapid detection of PG residues in duck meat.

\section{Materials and Methods}

2.1. Reagents and Equipment. Duck was purchased from the vegetable market of Jiangxi Agricultural University. PG standard substance $(99.8 \%)$ was purchased from standard substances network of China. Tetrachloroaurate trihydrate $\left(\mathrm{HAuCL}_{4} \cdot 3 \mathrm{H}_{2} \mathrm{O}, M=393.83\right.$, its $\mathrm{Au} \geq 49.0 \%$ ) was purchased from Sigma-Aldrich. Trisodium citrate, sodium chloride, acetonitrile, and hexane were of analytical grade. Ultrapure water was also used.

QE65000 portable Raman spectrometer (Ocean Optics Co., Ltd.), T6 series UV-Vis spectrophotometer (Beijing Purkinje General Instrument Co., Ltd.), laboratory ultrapure water machine (Kertong Water Co., Ltd.), wire coil heater (Beijing Yongxing Instrument Co., Ltd.), K-50B ultrasonic cleaner (Hefei Kinnic Machinery Co., Ltd.), FA1004B electronic balance (accuracy of $0.1 \mathrm{mg}$, Shanghai Flat Instrument Co., Ltd.), VORTEX-5 vortex mixer (Haimen, Jiangsu Province, Kylin-Bell Lab Instruments Co., Ltd.), HSC-24B termovap sample concentrator (Tianjin City Heng Austrian Science and Technology Development Co., Ltd.), JW-1024 low speed centrifuge (Anhui Jiaven Enqipment Industry Co., Ltd.), and quartz sampling bottle (Beijing Cheng Teng Equipment Co., Ltd.) were used.

\subsection{Experimental Methods}

2.2.1. Pretreatment of Duck Meat Extract. The duck meat extract $[6,15]: 5 \mathrm{~g}$ of duck meat mud, $2 \mathrm{~g}$ of anhydrous sodium sulfate, and $25 \mathrm{~mL}$ acetonitrile were added into $50 \mathrm{~mL}$ polypropylene centrifuge tube. The mixture was oscillated for $1 \mathrm{~min}$, followed by the ultrasonication treatment for $5 \mathrm{~min}$. After centrifuging the mixture at $4200 \mathrm{r} / \mathrm{min}$ for $10 \mathrm{~min}$, the supernatant of the mixture was removed. The above processes were repeated twice, and the supernatants were mixed. $4 \mathrm{~mL}$ of the supernatants with $8 \mathrm{~mL}$ of hexane saturated with acetonitrile was mixed, oscillated for $1 \mathrm{~min}$, and centrifuged at $4200 \mathrm{r} / \mathrm{min}$ for $8 \mathrm{~min}$. The hexane layer of the mixed solutions was removed, and the residual solutions were dried with nitrogen. The residue was dissolved in $4 \mathrm{~mL}$ ultrapure water, and the solutions were filtrated through a $0.45 \mu \mathrm{m}$ filter membrane to remove lipids. The duck meat extract was obtained and stored under the environment of $4^{\circ} \mathrm{C}$.

2.2.2. Synthesis of Au Nanoparticles. Au nanoparticles [16, 17]: $3 \mathrm{~mL}(1 \%)$ of auric chloride acid and $47 \mathrm{~mL}$ of ultrapure water were mixed in a $100 \mathrm{~mL}$ beaker, and the mixed solutions were heated with wire coil heater. After the boiling had commenced, $2 \mathrm{~mL}(1 \%)$ of trisodium citrate solution was added rapidly into the above boiling solution under a glass rod stirring. After $5 \mathrm{~min}$, the color of the mixed solution was changed to coffee. The synthesized Au nanoparticles were stored at the room temperature.

2.2.3. Standard Solution and Sample Solution. PG standard solution $\left(100 \mathrm{mg} \cdot \mathrm{L}^{-1}\right)$ : $10 \mathrm{mg}$ PG was dissolved in $100 \mathrm{~mL}$ duck meat extract. Sodium chloride standard solution $\left(0.1 \mathrm{mg} \cdot \mathrm{L}^{-1} \mathrm{NaCl}\right): 0.585 \mathrm{~g}$ of sodium chloride was dissolved in $100 \mathrm{~mL}$ ultrapure water.

The PG sample solution: the different volumes of PG standard solution were put into $10 \mathrm{~mL}$ centrifuge tube and the capacity was fixed to $5 \mathrm{~mL}$ using duck meat extract. Ultimately, the different mass concentrations of PG duck meat extract samples $(0.5,1.0,2.0,4.0,6.0,7.0,9.0,10.0,12.0$, and $15.0 \mathrm{mg} \cdot \mathrm{L}^{-1}$ ) were obtained through the above method.

$1 \mathrm{~mL}$ of Au nanoparticles, $20 \mu \mathrm{L}$ of sample solution (0.5 $\left.15.0 \mathrm{mg} \cdot \mathrm{L}^{-1}\right)$, and $100 \mu \mathrm{L}$ of $\mathrm{NaCl}$ solution $\left(0.1 \mathrm{mg} \cdot \mathrm{L}^{-1}\right)$ were sequentially added into the quartz sampling bottle. The mixture was well mixed, and then the SERS spectra were collected when the adsorption reaction lasted for $5 \mathrm{~min}$.

2.3. Parameter Settings of Instruments. Raman spectrometer parameter settings: the spectrometer's power and the laser wavelength were $700 \mathrm{~mW}$ and $785 \mathrm{~nm}$, respectively. The integration time of $10 \mathrm{~s}$, the average integral number of 2 , and the smoothness of 1 were applied.

UV-Vis spectrophotometer parameter settings: the display range and the scanning range were $0 \sim 2 s$ and $400 \sim$ $700 \mathrm{~nm}$, respectively. The interval of $2 \mathrm{~nm}$ and the spectrophotometric mode of Abs were selected. Finally, the absorption spectra were collected under the fast scan speed.

\section{Results and Discussion}

3.1. UV-Visible Absorption Spectra of Au Nanoparticles and SERS Assignment of PG. In the formation of sodium citrate reduction of auric chloride acid, the sodium citrate, which was not directly reacted with the boiling solution of auric chloride acid, was firstly decomposed into the stable acetoacetate and formic acid, and then Au nanoparticles were produced via the oxidation reaction between formic acid and auric chloride acid [18]. The sodium citrate was decomposed rapidly with electromagnetic heating, and the reactive substances were fused quickly [18]. Consequently, the smaller particle size and even distribution of Au nanoparticles could be synthetized. $500 \mu \mathrm{L}$ of $\mathrm{Au}$ nanoparticles was diluted with $2 \mathrm{~mL}$ ultrapure water, and the UV-Visible absorption spectra were collected. As shown in Figure 1, the maximum absorption peak of Au nanoparticles was $548 \mathrm{~nm}$ and the half-peak width was about $79 \mathrm{~nm}$. The results showed that the particle size of Au nanoparticle was somehow single and distributed uniformly [19].

The SERS spectra and structural formulas of PG were shown in Figure 2, and it can be seen that PG was mainly composed of the $\beta$-lactam ring, the thiazolidine ring, and the acyl side chain of the substituted benzene ring. As seen 


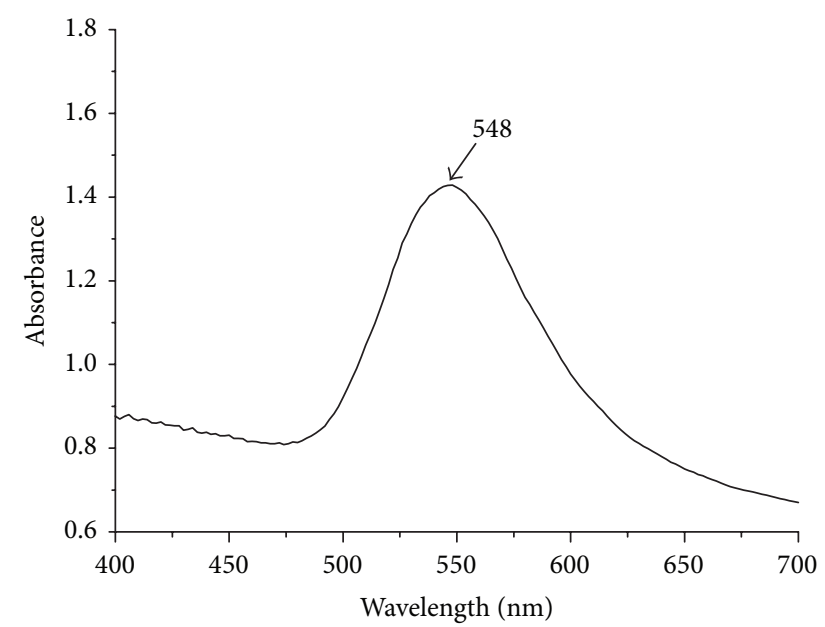

FIgURE 1: The UV-Visible absorption spectra of Au nanoparticles.

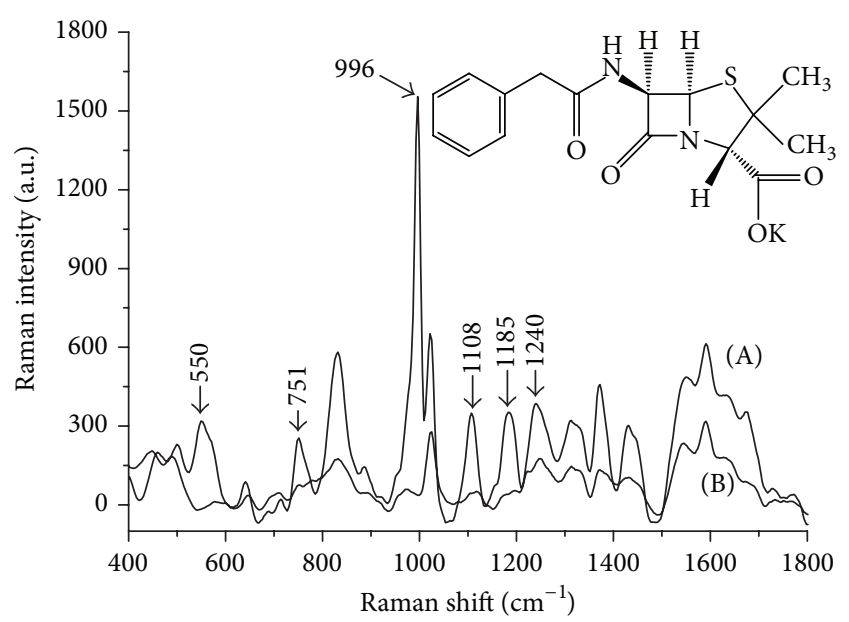

FIgURE 2: The SERS spectra and structural formulas of the PG: (A) Au nanoparticles + PG (7 mg/L), (B) Au nanoparticles.

from curves (A) and (B) in Figure 2, a visible difference was observed in the SERS spectra of Au nanoparticles and $\mathrm{Au}$ nanoparticles + PG at 550 1240 $\mathrm{cm}^{-1}$, which indicates that some interaction was produced between PG and Au nanoparticles. As shown from curve (A) in Figure 2, the SERS peak at $550 \mathrm{~cm}^{-1}$ might result from the deformation vibration of thiazole ring and benzene ring, the SERS speak at $751 \mathrm{~cm}^{-1}$ might be ascribed to the CC stretching vibration, and the SERS peak at $996 \mathrm{~cm}^{-1}$ might be ascribed to the stretching vibration of benzene ring and the breathing vibration of triangle ring. The SERS peak at $1108 \mathrm{~cm}^{-1}$ was possibly due to $\mathrm{CH}_{3}$ rocking vibration of plane and $\mathrm{C}-\mathrm{C}-\mathrm{C}$ bending vibration, the SERS peak at $1185 \mathrm{~cm}^{-1}$ was possibly due to CN stretching vibration and $\mathrm{CH}$ bending vibration of thiazole ring, and the SERS peak at $1240 \mathrm{~cm}^{-1}$ was possibly due to $\mathrm{CH}$ bending vibration and $\mathrm{C}-\mathrm{OH}$ stretching vibration from curve (A) [2023].

3.2. SERS Spectra of PG Solutions and PG Duck Meat Extract. The negative charge of Au nanoparticles resulted from many anions of citrate self-assembled on Au nanoparticles surface. Because of electrostatic repulsion of Au nanoparticles, $\mathrm{Au}$ nanoparticles remained stable in aqueous solution [24]. When the $\mathrm{NaCl}$ solution was added, the negative charge of Au nanoparticles was neutralized by the reaction with $\mathrm{Na}^{+}$. The neutralizing reaction led to the disappearance of $\mathrm{Au}$ nanoparticles electrostatic repulsion and the aggregation of $\mathrm{Au}$ nanoparticles. As a result, the signal of resonance light scattering was enhanced. As shown in Figure 3(a), when the $\mathrm{NaCl}$ solution was added into the mixture of Au nanoparticles and PG solution $\left(7 \mathrm{mg} \cdot \mathrm{L}^{-1}\right)$, the SERS signal of the mixture was further enhanced. In the comparison of curves (A) and (C) in Figure 3, the SERS peak of PG solution at $993 \mathrm{~cm}^{-1}$ was blue shifted about $3 \mathrm{~cm}^{-1}$. It can be also seen that the SERS peaks of PG solution at $1492 \sim 1674 \mathrm{~cm}^{-1}$ were excited from curves (A) and (B). The SERS peak at $1492 \mathrm{~cm}^{-1}$ might result from the $\mathrm{CH}_{3}$ bending vibration. The SERS peak at $1563 \mathrm{~cm}^{-1}$ might be attributed to double-peak vibration of degenerate ring, and the SERS peak at $1674 \mathrm{~cm}^{-1}$ might be ascribed to $\mathrm{C}=\mathrm{O}$ stretching vibration of peptide bond, $\mathrm{NH}$ and $\mathrm{CH}$ bending vibration [20-23].

Some constituents of duck meat, such as protein and fat, could significantly interfere with the SERS signal of PG. Therefore, the acetonitrile was firstly used as the extraction solvent to precipitate the protein in duck meat. Secondly, the hexane saturated with acetonitrile was used to remove fat and other impurities. The remaining acetonitrile was dried with nitrogen, and the residue was dissolved in ultrapure water. Finally, the relatively pure duck meat extract was obtained. Au nanoparticles + duck meat extract $+\mathrm{NaCl}, \mathrm{Au}$ nanoparticles + PG duck meat extract $\left(7 \mathrm{mg} \cdot \mathrm{L}^{-1}\right)+\mathrm{NaCl}$, and $\mathrm{Au}$ nanoparticles $+\mathrm{PG}\left(7 \mathrm{mg} \cdot \mathrm{L}^{-1}\right)+\mathrm{NaCl}$ were shown in Figure 3(b), and we could see that some SERS peaks of duck meat extract were the same with the SERS peaks of PG duck meat extract, such as $717 \mathrm{~cm}^{-1}, 1024 \mathrm{~cm}^{-1}, 1244 \mathrm{~cm}^{-1}$, and $1369 \mathrm{~cm}^{-1}$. The SERS spectra of PG duck meat extract presented the peaks at $993 \mathrm{~cm}^{-1}$ and $1492 \mathrm{~cm}^{-1}$, while the SERS spectra of duck meat extract did not present peaks at $993 \mathrm{~cm}^{-1}$ and $1492 \mathrm{~cm}^{-1}$. Meanwhile, the two SERS peaks of PG duck meat extract anastomosed with the SERS peaks of PG solution, which rendered a realistic basis for the detection of PG residues in duck meat.

3.3. Effect of Au Nanoparticles Addition on the SERS Intensity of PG Duck Meat Extract. The SERS effect is caused by the electromagnetic effect and the chemical effect, and the measured molecules are adsorbed onto the roughened surface of metal substrate. However, not all of the adsorbed molecules can produce the SERS effect on the surface of metal substrate. Most of the enhancement effect results from the portion of the adsorbed molecules on the positive surface of metal substrate. Therefore, the volume concentrations of $\mathrm{Au}$ nanoparticles are critical for the enhancement of SERS intensities [25, 26]. In this research, the volumes of PG duck meat extract $\left(7 \mathrm{mg} \cdot \mathrm{L}^{-1}\right)$ and the $\mathrm{NaCl}$ solution $(1 \mathrm{~mol} / \mathrm{L})$ were fixed to $50 \mu \mathrm{L}$ and $100 \mu \mathrm{L}$, respectively, and then the SERS spectra of the mixture with the addition of $0.5,0.7,1,1.2$, and $1.5 \mathrm{~mL}$ of $\mathrm{Au}$ nanoparticles were collected, respectively. 


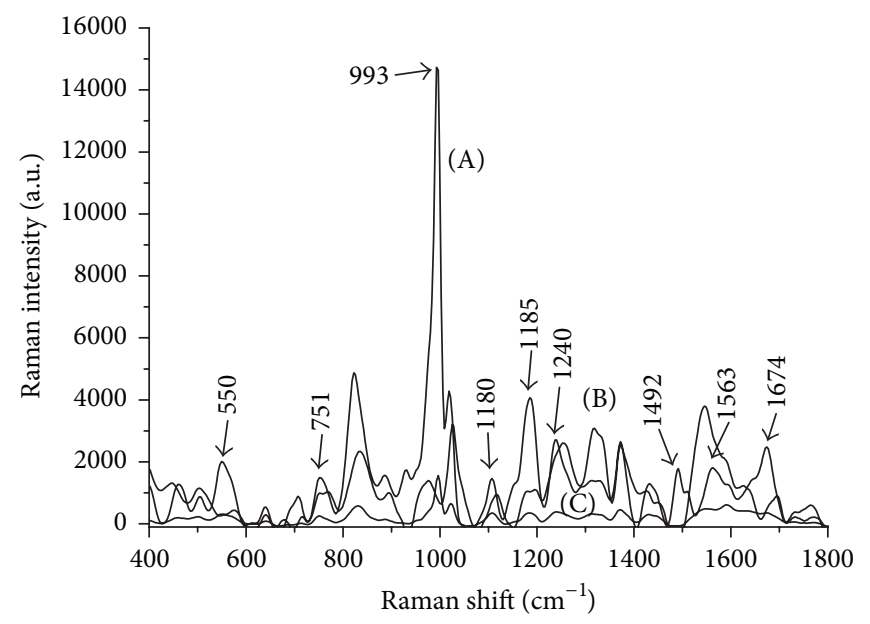

(a)

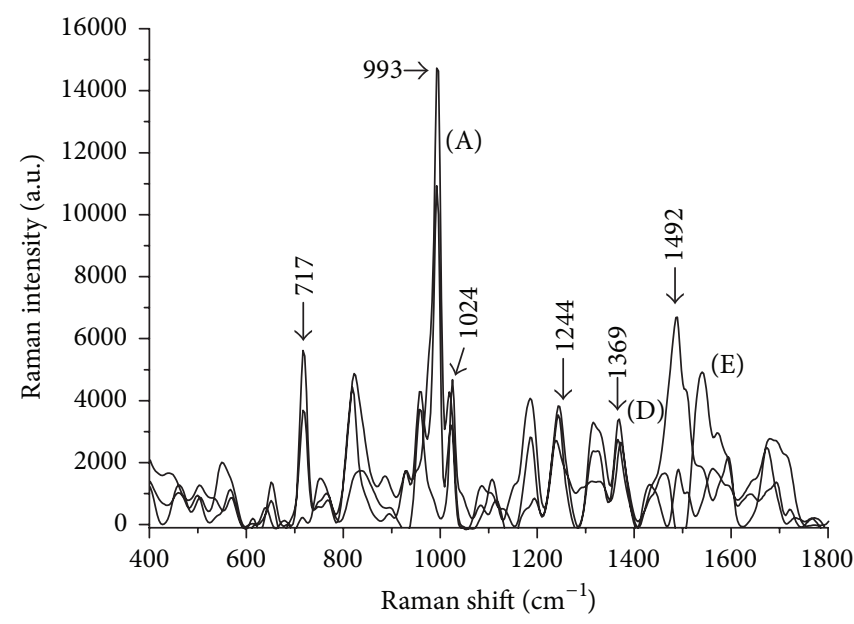

(b)

FIGURE 3: The SERS spectra of the PG solutions (a) and PG duck extract (b): (A) Au nanoparticles + PG (7 mg/L) + NaCl; (B) Au nanoparticles $+\mathrm{NaCl}$; (C) Au nanoparticles + PG $\left(7 \mathrm{mg} \cdot \mathrm{L}^{-1}\right)$; (D) Au nanoparticles + PG duck meat extract + NaCl; (E) Au nanoparticles + duck meat extract $+\mathrm{NaCl}$.

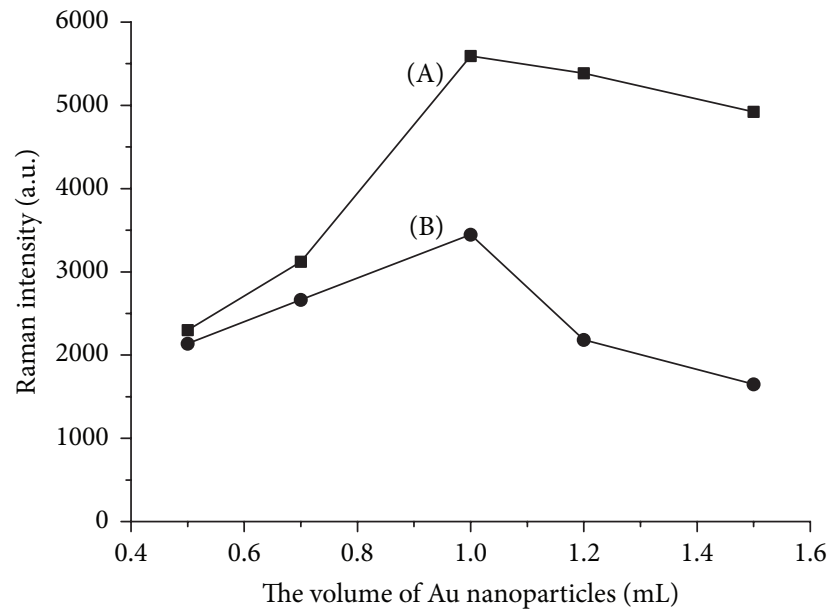

Figure 4: Effect of the $\mathrm{Au}$ nanoparticles addition on the SERS intensity of PG duck meat extract: (A) $993 \mathrm{~cm}^{-1}$, (B) $1492 \mathrm{~cm}^{-1}$.

As shown in Figure 4, the SERS intensities at $993 \mathrm{~cm}^{-1}$ and $1492 \mathrm{~cm}^{-1}$ were continuously strengthened with the increases of $\mathrm{Au}$ nanoparticles volume. However, when the volumes of $\mathrm{Au}$ nanoparticles exceeded $1 \mathrm{~mL}$, the SERS intensities decreased gradually. It is speculated that Au nanoparticles firstly adsorbed PG and the adsorption effect enhanced the Raman signal with the increases of Au nanoparticles volumes. However, when the volumes of $\mathrm{Au}$ nanoparticles increased to a certain value, the neutralization of $\mathrm{Na}^{+}$to $\mathrm{Au}$ nanoparticles could cover up the part of the PG adsorption effect and decreased the SERS intensities. Therefore, the $\mathrm{Au}$ nanoparticles addition was determined as $1 \mathrm{~mL}$ in the following experiment.

3.4. Effect of Sample Addition on the SERS Intensity of PG Duck Meat Extract. Owing to the portion of adsorbed

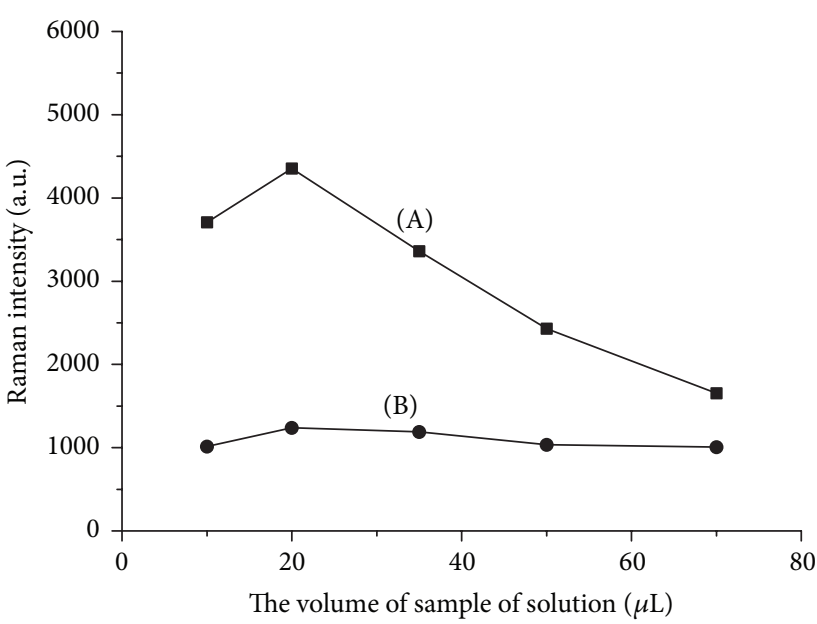

FIGURE 5: Effect of sample addition on the SERS intensity of PG duck meat extract: (A) $993 \mathrm{~cm}^{-1}$, (B) $1492 \mathrm{~cm}^{-1}$.

molecules on the positive surface of metal substrate, the volume concentration of the sample solution $(7 \mathrm{mg} / \mathrm{L})$ could impact the SERS intensity of PG duck meat extract. When Au nanoparticles and the $\mathrm{NaCl}$ solution were fixed, respectively, in this paper, the SERS spectra of the different volumes of the sample solutions $(10,20,35,50$, and $70 \mu \mathrm{L})$ were collected and analyzed. As seen from Figure 5, when the volumes of the sample solutions increased from $10 \mu \mathrm{L}$ to $20 \mu \mathrm{L}$, the SERS intensities at $993 \mathrm{~cm}^{-1}$ and $1492 \mathrm{~cm}^{-1}$ were enhanced. However, when the volumes were more than $20 \mu \mathrm{L}$, the SERS intensities decreased gradually. Therefore, the sample addition was selected as $20 \mu \mathrm{L}$ in the following experiment.

3.5. Effect of $\mathrm{NaCl}$ Addition on the SERS Intensity of $P G$ Duck Meat Extract. The larger particle size of aggregate, which was caused by the adsorbed PG on the surface of $\mathrm{Au}$ 


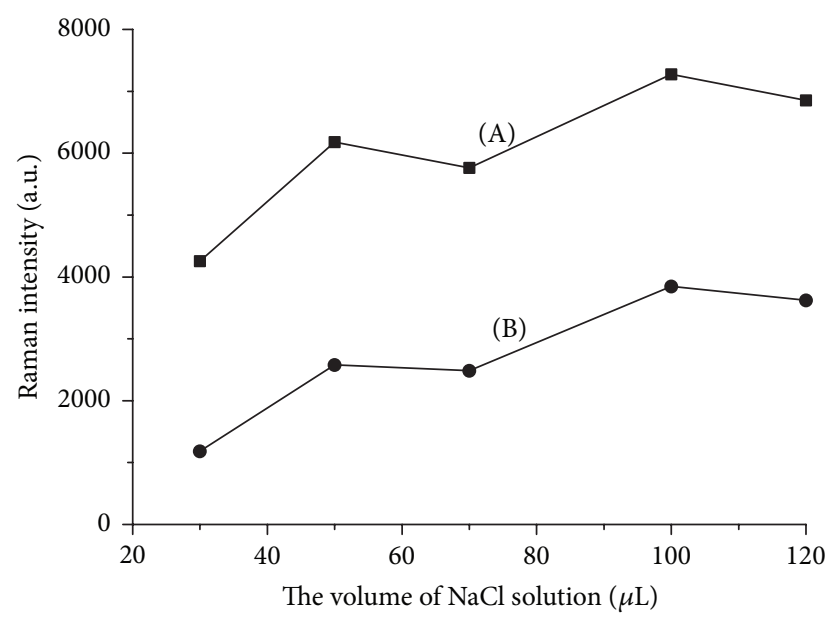

FIGURE 6: Effect of $\mathrm{NaCl}$ addition on the SERS intensity of PG duck meat extract: (A) $993 \mathrm{~cm}^{-1}$, (B) $1492 \mathrm{~cm}^{-1}$.

nanoparticles, would result in the local plasma resonance between PG and Au nanoparticles and the enhancement of SERS intensities [27]. When the $\mathrm{NaCl}$ solution was added into the mixture of Au nanoparticles + PG duck meat extract, $\mathrm{Au}$ nanoparticles would gather rapidly and the color of the mixture was changed from coffee to blue. The particle size of the above Au nanoparticles became bigger, which is manifested as the enhancement of the resonance light scattering, and the SERS intensities of PG duck meat extract were further enhanced. In order to investigate the effects of different volume concentrations of the $\mathrm{NaCl}$ solution on the SERS intensities of the mixture, $1 \mathrm{~mL}$ of Au nanoparticles and $20 \mu \mathrm{L}$ of PG duck meat extract were firstly added into the quartz sampling bottle in turn. And, then, different volumes of the $\mathrm{NaCl}$ solution $(30,50,70,100$, and $120 \mu \mathrm{L})$ were added, respectively, and their SERS spectra were collected. When the $\mathrm{NaCl}$ addition was $100 \mu \mathrm{L}$, the SERS intensities at $993 \mathrm{~cm}^{-1}$ and $1492 \mathrm{~cm}^{-1}$ reached the maximum value in Figure 6 . The reason was probably that the proper volume of $\mathrm{NaCl}$ solution could have the effect of the activator, but the excess volume of the $\mathrm{NaCl}$ solution made the mixture produce the coagulation and resulted in the SERS intensities weakening [28]. The experimental results indicated that $100 \mu \mathrm{L}$ of the $\mathrm{NaCl}$ solution was the optimum addition, so the $\mathrm{NaCl}$ addition was selected as $100 \mu \mathrm{L}$ in the following experiment.

3.6. Effect of Adsorption Time on the SERS Intensity of PG Duck Meat Extract. When the volumes of Au nanoparticles, PG duck meat extract, and the $\mathrm{NaCl}$ solution were fixed, respectively, the adsorption time had some influences on the enhancement effect of SERS intensities. After $1 \mathrm{~mL}$ of $\mathrm{Au}$ nanoparticles, $20 \mu \mathrm{L}$ of PG duck meat extract and $100 \mu \mathrm{L}$ of the $\mathrm{NaCl}$ solution were mixed together, $\mathrm{Au}$ nanoparticles would gather, and then the aggregation of $\mathrm{Au}$ nanoparticles would produce the SERS spectra. When the adsorption times of the mixture were $1,5,10,15$, and 20 min, respectively, the SERS spectra of the mixture in different adsorption times were collected. As shown from curve (A) in Figure 7, the SERS

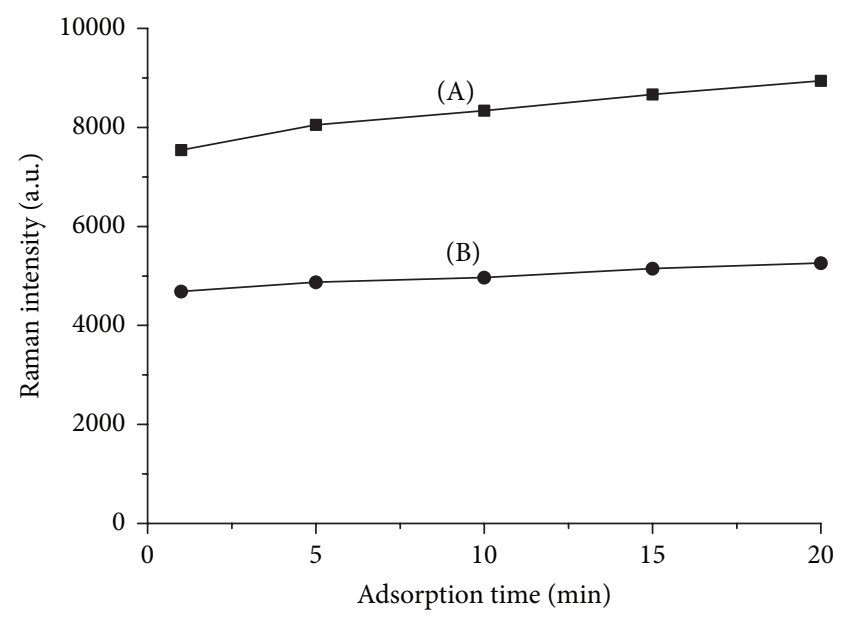

FIGURE 7: Effect of adsorption time on the SERS intensity of PG duck meat extract: (A) $993 \mathrm{~cm}^{-1}$, (B) $1492 \mathrm{~cm}^{-1}$.

intensities at $993 \mathrm{~cm}^{-1}$ were of larger increasing range at 1 $5 \mathrm{~min}$. Although the SERS intensities had some enhancement effect at 5 20 $\mathrm{min}$, the enhancement extent was relatively stable. As seen from curve (B) in Figure 7, the SERS intensities at $1492 \mathrm{~cm}^{-1}$ were enhanced gradually at $1 \sim 20 \mathrm{~min}$, but the enhancement extent did not change obviously. The above results might be because the PG molecules in duck meat extract could not be completely adsorbed on the surface of $\mathrm{Au}$ nanoparticles before $5 \mathrm{~min}$, so the SERS intensities at $993 \mathrm{~cm}^{-1}$ and $1492 \mathrm{~cm}^{-1}$ were continuously enhanced. After $5 \mathrm{~min}$, the PG molecules might be completely adsorbed on the surface of Au nanoparticles. Therefore, the SERS spectra were collected after the reaction for $5 \mathrm{~min}$.

3.7. Prediction and Analysis Model. The proposed method based on SERS with Au nanoparticles was employed to determine PG residues in duck meat. The different mass concentrations of PG duck meat extract samples were prepared and the SERS spectra were collected under the optimum conditions. The research showed that when the concentration range of PG in duck meat extract was 0.5 $15.0 \mathrm{mg} \cdot \mathrm{L}^{-1}$, the SERS intensities at $993 \mathrm{~cm}^{-1}$ and $1492 \mathrm{~cm}^{-1}$ showed the enhancement trend with the increasement of PG concentrations. When the mass concentration of PG in duck meat extract was lower than $4 \mathrm{mg} \cdot \mathrm{L}^{-1}$, the SERS peak at $1492 \mathrm{~cm}^{-1}$ was hardly observed. However, the SERS peak at $993 \mathrm{~cm}^{-1}$ could be observed under the same conditions when the mass concentration of PG in duck meat extract was $0.5 \mathrm{mg} \cdot \mathrm{L}^{-1}$. Therefore, the PG duck meat extract samples (the concentration range of $0.5 \sim 15.0 \mathrm{mg} \cdot \mathrm{L}^{-1}$ ) and the SERS intensities at $993 \mathrm{~cm}^{-1}$ were utilized for the quantitative analysis.

The calibration curve between the mass concentrations of PG in duck meat extract and the SERS intensities at $993 \mathrm{~cm}^{-1}$ was established using 6 samples, and 4 of the remaining samples were used to verify the accuracy of the calibration curve. As shown in Figure 8 and Table 1, when the concentration range of PG in duck meat extract 


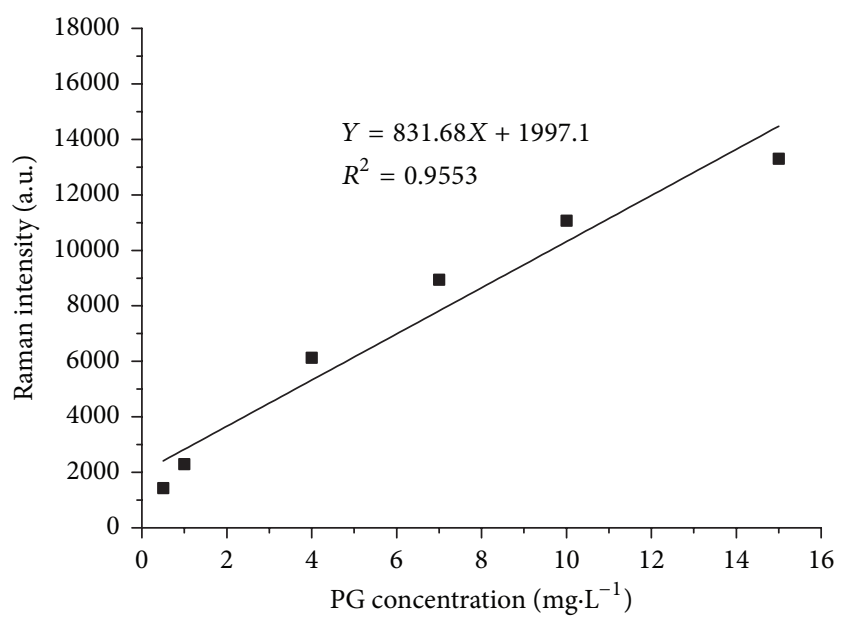

(a)

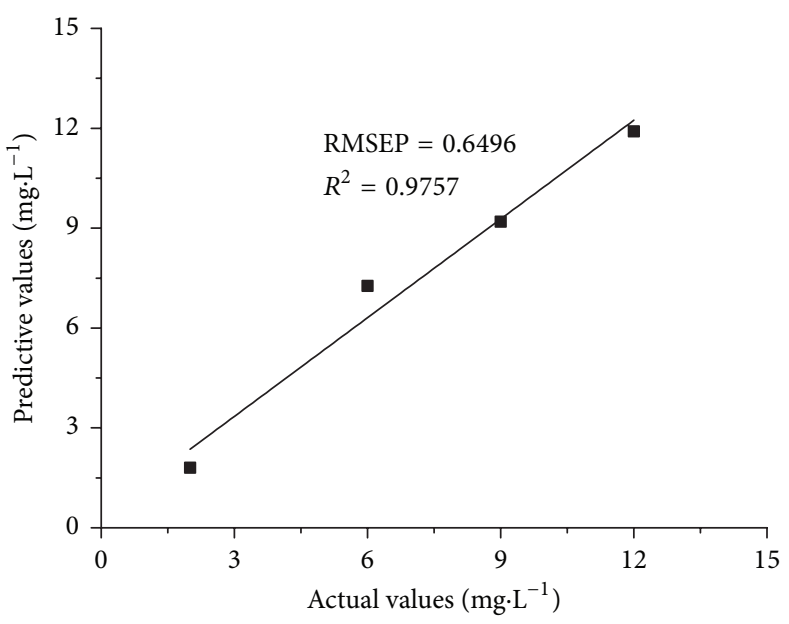

(b)

FIgURE 8: Linear equation of the PG duck extract (a) and the relationship of the prediction samples (b).

TABLE 1: Determined results of the recovery rate.

\begin{tabular}{lccc}
\hline $\begin{array}{l}\text { Sample } \\
\text { number }\end{array}$ & $\begin{array}{c}\text { Concentration of PG } \\
\text { in duck meat } \\
\text { extract } /\left(\mathrm{mg} \cdot \mathrm{L}^{-1}\right)\end{array}$ & $\begin{array}{c}\text { Recovery } \\
\text { amount } /\left(\mathrm{mg} \cdot \mathrm{L}^{-1}\right)\end{array}$ & $\begin{array}{c}\text { Recovery } \\
\text { rate/\% }\end{array}$ \\
\hline 1 & 2 & 1.81 & 90.3 \\
2 & 6 & 7.27 & 121.1 \\
3 & 9 & 9.19 & 102.2 \\
4 & 12 & 11.91 & 99.3 \\
\hline
\end{tabular}

was $0.5 \sim 15.0 \mathrm{mg} \cdot \mathrm{L}^{-1}$, there was a good linear relationship between the concentrations of PG in duck meat extract and the SERS intensities at $993 \mathrm{~cm}^{-1}$. The linear equation was $Y=831.68 X+1997.1$, and the determination coefficient was 0.9553 . The determination coefficient of PG in duck meat extract between the actual values and the predictive values was 0.9757 , and the root mean square error (RMSEP) was $0.6496 \mathrm{mg} \cdot \mathrm{L}^{-1}$. The recovery rate of $\mathrm{PG}$ in duck meat extract was $90 \sim 121 \%$. The result showed that the proposed method was feasible and relatively reliable using SERS with $\mathrm{Au}$ nanoparticles for the rapid detection of $\mathrm{PG}$ residues in duck meat.

\section{Conclusions}

Firstly, the absorption spectra of Au nanoparticles, the SERS spectra of PG solution, and PG duck meat extract and their vibrational assignment were analyzed, and these analyses could provide the realistic basis for the detection of PG residues in duck meat. Secondly, the effects of Au nanoparticles addition, sample addition, $\mathrm{NaCl}$ solution addition, and adsorption time on the SERS intensities of PG duck meat extract were discussed, respectively, and their optimal experimental conditions were determined, respectively. Finally, the SERS spectra of 10 samples with different mass concentrations of PG in duck meat extract were collected under the optimal conditions, and the model of $\mathrm{PG}$ residues in duck meat extract was established and analyzed. The result showed that a good linearity was obtained between the SERS intensities at $993 \mathrm{~cm}^{-1}$ and the concentrations of PG in duck meat extract in the range of $0.5 \sim 15 \mathrm{mg} \cdot \mathrm{L}^{-1}, Y=831.68 X+1997.1$, and the determination coefficient was 0.9553 . The determination coefficient of PG in duck meat extract between the actual values and the predictive values was 0.9757 , the root mean square error (RMSEP) was $0.6496 \mathrm{mg} \cdot \mathrm{L}^{-1}$, and the recovery rate was $90 \sim 121 \%$. The experimental results indicated that it was feasible that SERS with Au nanoparticles was used for the rapid detection of $\mathrm{PG}$ residues in duck meat.

\section{Competing Interests}

The authors declare that they have no competing interests.

\section{Acknowledgments}

This research was supported by External Science and Technology Cooperation Plan of Jiangxi Province, China (20132BDH80005), and National Natural Science Foundation of China (31101295). Additional support for this research was provided by the Science and Technology Support Project of Jiangxi Province, China (2012BBG70058).

\section{References}

[1] C. J. Liu, H. Wang, Z. X. Du, Y. B. Jiang, J. H. Shan, and Y. H. Cai, "Simultaneous determination of 2 penicillins and their 5 major metabolites in bovine muscle by ultra performance liquid chromatography tandem mass spectrometry," Chinese Journal of Analytical chemistry, vol. 36, no. 5, pp. 617-622, 2011.

[2] Y. Q. Liu and P. S. Ma, "Determination of diffusion coefficient of benzylpenicillin potassium in aqueous solution," Chemical Industry and Engineering, vol. 15, no. 3, pp. 6-14, 1998.

[3] M. H. Han, C. Q. Gu, X. Y. Hu et al., "Identification and virulence of four enterococcus strains isolated from ducks," 
Chinese Journal of Veterinary Science, vol. 27, no. 6, pp. 821-829, 2007.

[4] X. L. Cai, Q. Wei, Y. S. Cui et al., "Serotype identification and drug sensitivity test of 22 strains of riemerella anatipes-tifersis isolated from ducks in Zhejiang province," Acta Agriculturae Zhejiangensis, vol. 19, no. 1, pp. 46-49, 2007.

[5] X. J. Li, L. Li, J. Ma, Y. Xue, and G. H. Wu, "Determination of residues penicillin in chicken muscle by an electrochemical immunosensor," Chines Journal of Applied Chemistry, vol. 26, no. 6, pp. 716-720, 2009.

[6] C. Wang and X. Wang, "Determination of 5 penicillin residues in pork by high performance liquid chromatography with precolumn derivatization," Chinese Journal of Analytical Chemistry, vol. 29, no. 7, pp. 779-781, 2001.

[7] K. Y. Zhang, D. J. Wang, Z. H. Yuan, and S. X. Fan, "Determination of Ampicillin residues in chicken meat and swineport," Chinese Journal of Veterinary Science, vol. 24, no. 5, pp. 470-472, 2004.

[8] K. Jiang, Y. P. Chen, Y. F. Jin, J. F. Huang, X. Z. Chen, and D. L. Zhang, "Application of enzyme-linked immunosorbent assay in detecting $\beta$-lactam antibiotic residues in dairy products," China Dairy Industry, vol. 38, no. 1, pp. 51-54, 2010.

[9] B. S. Jia, W. L.-J. Ha-si, X. Lin, F. Yang, S. Lin, and Z. W. Lv, "Preparation of raman surface-enhangced scattering substrate and its application," Journal of Food Safety and Quality, vol. 5, no. 5, pp. 1490-1494, 2014.

[10] Y. Wang, W. S. Chen, Z. F. Hua et al., "Diagnosis of esophageal tissue based on surface-enhanced Raman spectroscopy," Scientia Sinica Vitae, vol. 43, no. 6, pp. 525-532, 2013.

[11] M.-H. Zhou, C.-Y. Liao, Z.-Y. Ren, H.-M. Fan, and J.-T. Bai, "Bioimaging technologies based on surface-enhanced Raman spectroscopy and their applications," Chinese Optics, vol. 6, no. 5, pp. 633-642, 2013.

[12] C. V. Di Anibal, L. F. Marsal, M. P. Callao, and I. Ruisánchez, "Surface Enhanced Raman Spectroscopy (SERS) and multivariate analysis as a screening tool for detecting Sudan I dye in culinary spices," Spectrochimica Acta-Part A: Molecular and Biomolecular Spectroscopy, vol. 87, pp. 135-141, 2012.

[13] J.-Q. Tang, C. Tian, C.-Y. Zeng, and S.-Q. Man, "Alkaline silver colloid for surface enhanced Raman scattering and application to detection of melamine doped milk," Spectroscopy and Spectral Analysis, vol. 33, no. 3, pp. 709-713, 2013.

[14] X. Y. Zhu, Studies on the Detection of Nitrofuran Antibiotics by Surface-Enhanced Raman Scattering, Jiangnan University, Wuxi, China, 2013.

[15] X. M. Li, Y. Z. Cao, J. J. Zhang, J. Mu, L. Wang, and H. Q. Wang, "Determination of 9 penicillins in fugu and eel by high pressure liquid chromatography-electrospray tandem mass spectrometry," Journal of Food Safety and Quality, vol. 4, no. 4, pp. 1165-1172, 2013.

[16] P. Liu, B. Y. He, and Y. F. Huang, "The rapid diagnostic stripe of the candida albicans in cow mastitis," China, 201310674116. 9, 2013.

[17] W. Ji, Studies on the detection of chloramphenicol and its sodium succinate by surface-enhanced raman scattering [M.S. thesis], Jiangnan University, Jiangsu, China, 2013.

[18] L. Wang, S. H. Huang, Z. F. Huang et al., "Rapid synthesis of gold colloids assisted by microwave irradiation and SERS activity characterized," The Journal of Light Scattering, vol. 26, no. 1, pp. 13-18, 2014.
[19] Q. Zhang and Y. X. Weng, "A possible mechanism for the reduces fluorescence quantum efficiency of bacteriochlorophyll a molecules adsorbed on the gold nanoparticles," The Journal of Light Scattering, vol. 27, no. 1, pp. 1-8, 2015.

[20] X. Y. Qin, H. M. Sui, R. Li et al., "Study on surface enhanced raman spectroscopy of benzylpenicillin sodium drug molecule," Spectroscopy and Spectral Analysis, vol. 34, no. 10, pp. 253-254, 2014.

[21] X. F. Qian, Y. Shi, J. T. Zhao, and W. Shi, "Studies of penicillins by micro raman spectroscopy," Spectroscopy and Spectral Analysis, vol. 22, no. 1, pp. 51-53, 2002.

[22] Q. Q. Kang and G. M. Zhou, "Study on amoxicillin and the interaction with DNA by spectrometric methods," The Journal of Light Scattering, vol. 23, no. 4, pp. 368-375, 2011.

[23] W. Z. Liang, The Application of Raman Spectroscopy in Antibiotic Drug, Tianjin University, Tianjin, China, 2012.

[24] Y. N. Zhang, Synthesis and Interaction with DNA of Polypyridine Copper Complexes, Henan Normal University, Henan, China, 2013.

[25] Z. Y. Zhu, R. A. Gu, and T. H. Lu, Application of Raman spectroscopy in Chemistry, Northeastern University Press, Shenyang, China, 1998.

[26] X. G. Yang and Q. L. Wu, Raman Spectroscopy Analysis and Application, National Defense Industry Press, Beijing, China, 2008.

[27] Y. Q. He, S. P. Liu, Z. F. Liu, X. L. Hu, and Q. M. Lu, "Resonance rayleigh scattering spectral method for the determination of kanamycin with gold nanoparticle as probe," Acta Chimica Sinica, vol. 63, no. 11, pp. 997-1002, 2005.

[28] L. Lin, The Qualitative and Quantitative Analysis of Pesticide Residue in Tea Using Surface-Enhanced Raman Spectroscopy (SERS), Jiangxi Agricultural University, Nanchang, China, 2014. 

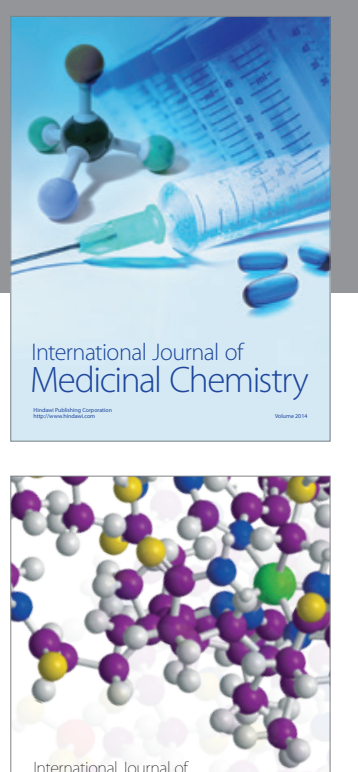

Carbohydrate Chemistry

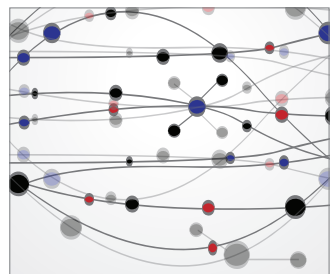

The Scientific World Journal
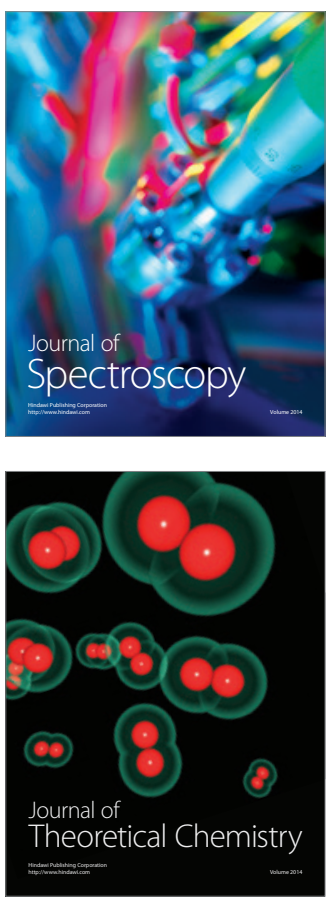
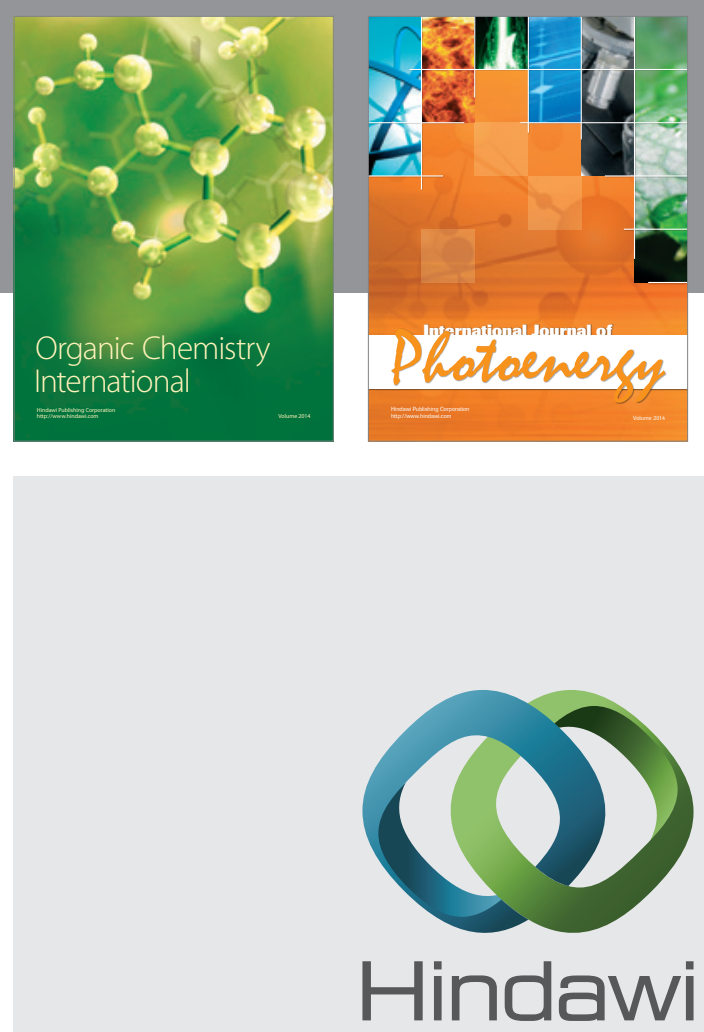

Submit your manuscripts at

http://www.hindawi.com

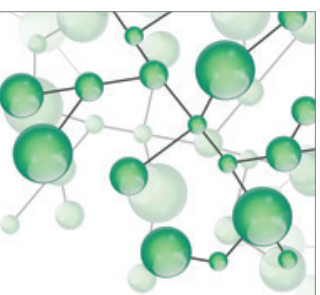

International Journal of

Inorganic Chemistry

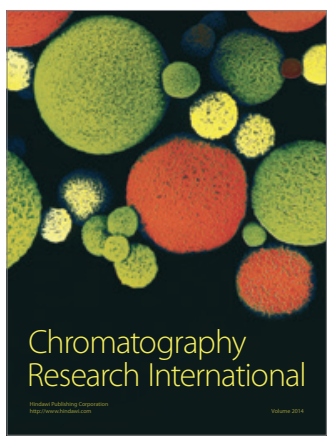

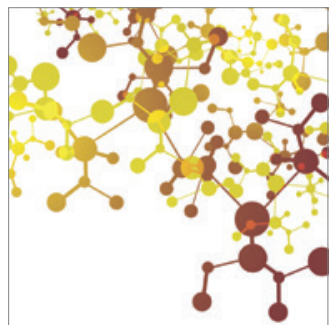

Applied Chemistry
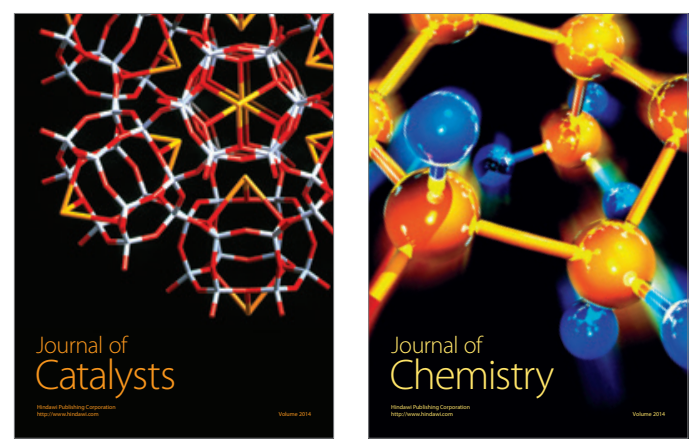
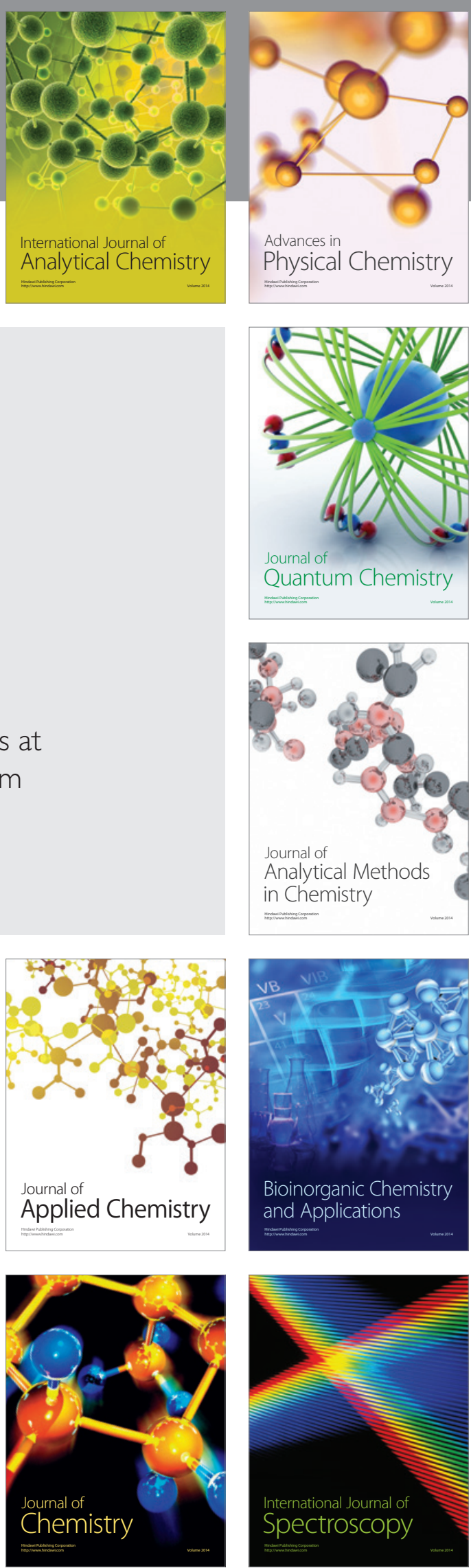